\title{
Evaluation of Apoptotic and Growth Inhibitory Activity of Phloretin in BGC823 Gastric Cancer Cell
}

\author{
Mingqian $\mathrm{Lu}^{1,2,3}$, Qingzhi Kong ${ }^{1,4 *}$, Xinhua $\mathrm{Xu}^{2,3}$, Hongda $\mathrm{Lu}^{4}$, Zhongxin $\mathrm{Lu}^{4}$, Wei \\ $\mathrm{Yu}^{2,3}$, Bin Zuo ${ }^{2,3}$, Jin $\mathrm{Su}^{2,3}$ and Rong Guo ${ }^{2,3}$ \\ ${ }^{1}$ Hubei University of Chinese Medicine, Wuhan 430061, ${ }^{2}$ Institute of Oncology, China Three Gorges University, ${ }^{3}$ Oncology \\ Department, Yichang Central Hospital,Yichang 443000, "Wuhan Central Hospital \& Wuhan Institute of Oncology, Wuhan \\ 430061, China
}

*For correspondence: Email: lumqyc@sina.cn; Tel: +86-0717-6486745; Fax: +86-0717-6486745

Received: 19 June 2014

Revised accepted: 8 December 2014

\begin{abstract}
Purpose: To evaluate the in vitro anti-proliferative activity and probable mechanism of phloretin in human gastric cancer BGC823 cell lines.

Methods: Phloretin was isolated from apple tree leaves and identified by ${ }^{1} \mathrm{H}$-Nuclear Magnetic Resonance (NMR), ${ }^{13} \mathrm{C}-N M R$ and electrospray ionization tandem mass spectrometry (ESI-MS). The inhibitory activity of the compound in BGC823 gastric cancer cells was determined by Methylthiazolyldiphenyl-tetrazolium bromide (MTT) assay and soft agar colony formation assay while its apoptotic activity was detected by fluorescene staining and Western blotting analysis.

Results: The results show that the inhibitory activity of phloretin in BGC823 gastric cancer cells was mediated by induction of apoptosis and down-regulation of Bc/2 (B-cell lymphoma 2) expression. The anti-proliferative effects of phloretin was dose-dependent and inhibited the growth of BGC823 gastric cancer cells by $73 \%$ at $30 \mu \mathrm{M}$; this effectively induced cleavage of anti-poly (ADP-ribose) polymerase $(P A R P)$ as well as downregulation of Bc/2 protein expression in BGC823 cells after $24 \mathrm{~h}$ treatment. Conclusion: Phloretin is a promising preventive and therapeutic agent for gastric cancer.
\end{abstract}

Keywords: Phloretin, Gastric cancer, Apoptosis, $\beta$-Cell lymphoma 2, Anti-poly (ADP-ribose) polymerase

Tropical Journal of Pharmaceutical Research is indexed by Science Citation Index (SciSearch), Scopus, International Pharmaceutical Abstract, Chemical Abstracts, Embase, Index Copernicus, EBSCO, African Index Medicus, JournalSeek, Journal Citation Reports/Science Edition, Directory of Open Access Journals (DOAJ), African Journal Online, Bioline International, Open-J-Gate and Pharmacy Abstracts

\section{INTRODUCTION}

Gastric cancer is the second leading cause of cancer deaths and remains the fourth most common cancer worldwide [1]. The 5-year survival rate among gastric cancer patients is still $<40 \%$, which is mainly due to relapse and metastasis. Numerous factors are closely related with a high risk of gastric cancer, such as Helicobacter pylori infection, smoking, and iodine deficiency [2]. Furthermore, smoked foods, saltrich foods and pickled vegetables are associated with a high risk of gastric cancer [3,4]. On the other hand, fresh fruits and vegetables are associated with a lower risk of gastric cancer [4].

Phloretin is a chalcone, which is a kind of flavonoid recognized to have health-promoting benefits, including antioxidant [5], antiinflammation [6], disease-preventing and chemopreventive activities [7]. Phloretin is mainly found in apples and strawberries [8-10]. It has numerous biological properties, including reduction of human platelets activity, competitive inhibition of sodium-glucose cotransporters (SGLTs), inhibition of cardiovascular disease and 
anticarcinogenic activity $[11,12]$. Compared with other flavonoids, however, few studies have investigated the anti-tumor potential of phloretin. In this study, we investigated the inhibitory effects of phloretin in BGC823.

\section{EXPERIMENTAL}

\section{Plant extracts}

Apple leaf extracts (one pack, $500 \mathrm{~g}$ ) were purchased from Snow biological technology co., LTD (Xi'an, China).

\section{Equipment and chemicals}

The ${ }^{1} \mathrm{H}$ - and ${ }^{13} \mathrm{C}$-NMR spectra were recorded on a Bruker Avance-400 FT-NMR spectrometer, with TMS internal standard. ESI-MS were recorded on 3200 Q-trap ESI-MS spectrometer ( $\mathrm{ABI}$, American). Column chromatography was carried on silica gel (200-300 mesh) and Sephadex LH-20 (Pharmacia Co.). All the organic solvents used were of analytical grade and purchased from Sinopharm Chemical Reagent Co., Ltd (Shanghai, China). Bcl2 and Bax were purchased from Santa Cruz Biotechnology, Inc. Anti- $\beta$-actin and Anti-poly (ADP-ribose) polymerase (PARP) were obtained from Sigma Chemical Company (Sigma-Aldrich). Immobilon Western Chemiluminescent HRP Substrate Kit was obtained from Millipore. The cell culture medium (RPMI-1640, Roswell Park Memorial Institute 1640) and fetal bovine serum (FBS) were purchased from Hyclone Company (Logan, Utah, USA). Acrylamide-bis solution (30 $\%$; 29:1) was bought from Bio-Radlaboratories, Inc (Hercules, CA, USA). Protein content was tested using a BCA kit (Thermo Scientific).

\section{Cell line and cultures}

Human gastric cancer cell lines, BGC823, were purchased from Institute of Cell Biology (Shanghai, China, Cells were maintained in RPMI-1640 (Roswell Park Memorial Institute 1640).

\section{Extraction and isolation of phloretin}

Extract powder $(200 \mathrm{~g})$ was suspended in $2 \mathrm{~L}$ Millipore-filtered water and successively extracted with chloroform, ethyl acetate and nbutanol ( $3 \times 2 \mathrm{~L}$ for each solvent), respectively. The ethyl acetate fraction (EAF) yielded $42 \mathrm{~g}$ dry extract. The $40 \mathrm{~g}$ EAF were purified on silica gel chromatography column eluted with $\mathrm{CHCl}_{3}$ $\mathrm{MeOH}$ gradient (from 20:1 to $4: 1, \mathrm{v} / \mathrm{v}$ ) and further purified by C-18 and Sephadex LH-20 to get the main apple polyphenol compound $(2.3 \mathrm{~g})$. The compound was characterized by NMR using CD3OD as solvent for measurement and ESI-MS (negative ionization TIC modes, the $\mathrm{m} / \mathrm{z}$ values of the monitored ions were from 100 to 800 ) spectral analysis and identified as phloretin.

\section{MTT analysis}

MTT assay (Cell titer 96॰R Aqueous One Solution Cell Proliferation Assay, Promega) was used to assess the inhibition effect of phloretin. Briefly, BGC823 $\left(2 \times 10^{3} /\right.$ well $)$ were seeded in 96-well plates. BGC823 cells were treated with different concentration of phloretin (10, 20 and 30 $\mu \mathrm{M}$, respectively) for $24 \mathrm{~h}$, then phloretin was removed, fresh culture media added for additional 5 days. The MTT assay was performed using iMarkmicroplate Absorbance Reader (Bio-RAD, Richmond, CA) according to the manufacturer's instructions.

\section{Soft agar colony formation assay}

Triplicate samples of cells $\left(1 \times 10^{3}\right)$ were resuspended in $1 \mathrm{ml}$ of RPMI-1640 medium containing $0.3 \%$ low-melt agarose, supplemented with $10 \%$ fetal bovine serum, 50 units $/ \mathrm{ml}$ penicillin and $50 \mu \mathrm{g} / \mathrm{ml}$ streptomycin. BGC823 cells were treated with $10,20,30 \mu \mathrm{M}$ phloretin and plated on top of solidified layer with the same RPMI-1640 medium containing $0.6 \%$ low-met agarose. Plates were incubated for 3 weeks at $37{ }^{\circ} \mathrm{C}$ in $5 \% \mathrm{CO}_{2}$ in humidified incubator. Then colony formation was stained with $0.01 \%$ crystal violet and photographed and counted.

\section{Cell extraction and western blotting}

Western Blots were performed according to the protocols described elsewhere [13]. Cell lysates were prepared with the lysis buffer followed by centrifugation. Approximately $30 \mu \mathrm{g}$ of denatured protein was resolved on $12 \%$ SDS-PAGE and electroblotted onto nitrocellulose membranes (Amersham, Salt Lake City, UT, USA). After blocking, membranes were incubated with antibodies against PARP at a dilution of 1:1000 or antibodies against Bcl2 at a dilution of 1:1000 or antibodies against Bax at a dilution of 1:1000 or antibodies against $\beta$-actin at a dilution of $1: 5000$ at $4{ }^{\circ} \mathrm{C}$ overnight followed by further incubation with a secondary antibody (1:2000). After washing with Tris-buffer saline containing $0.05 \%$ Tween 20, the blots were detected by chemiluminescence followed by exposure to Kodak-X-Omat film (Shanghai, China). 


\section{Statistical analysis}

Results are expressed as the means \pm SEM. Statistical significance was determined by Student's t test or a one-way or two-way analysis of variance (ANOVA) followed by Turkey's test, as appropriate using Graphpad Prism statistics software (Graphpad Software). A $p$-value of < 0.05 was considered statistically significant $\left({ }^{*} p<\right.$ $\left.0.05,{ }^{* *} p<0.01,{ }^{* * *} p<0.001\right)$.

\section{RESULTS}

\section{NMR and ESI-MS spectral analysis the main apple polyphenol}

The compound was obtained as a white powder, and $t$ UV spectrum showed $\lambda_{\max }$ at $285 \mathrm{~nm}$; ESIMS yielded a quasi-molecular ion peak [M-H]- at $\mathrm{m} / \mathrm{z} 273.2$ [M - H]. ${ }^{1} \mathrm{H}-\mathrm{NMR}\left(400 \mathrm{MHz}, \mathrm{CD}_{3} \mathrm{OD}\right)$ spectrum showed an AA'BB' system at $\delta 6.59$ ppm $\left(2 \mathrm{H}, \mathrm{d}, \mathrm{J}=7.0 \mathrm{~Hz}, \mathrm{H}-3^{\prime}, 5^{\prime}\right)$ and $7.01(2 \mathrm{H}, \mathrm{d}$, $\left.\mathrm{J}=7.0 \mathrm{~Hz}, \mathrm{H}-2^{\prime}, 6^{\prime}\right)$. Two meta coupled protons at $\delta 5.91(1 \mathrm{H}$, brs, $\mathrm{H}-8)$ and $6.04(1 \mathrm{H}, \mathrm{brs}, \mathrm{H}-6)$. Two methylene signals at $\delta 3.20(2 \mathrm{H}, \mathrm{t}, \mathrm{J}=7.6$ $\mathrm{Hz}, \mathrm{H}-3)$ and $2.58(2 \mathrm{H}, \mathrm{t}, \mathrm{J}=7.6 \mathrm{~Hz}, \mathrm{H}-2) .{ }^{13} \mathrm{C}-$ NMR (100 MHz, $\left.\mathrm{CD}_{3} \mathrm{OD}\right)$ ס: 29.4 (C-2), 45.6 (C3), 114.6 (C-3', 5'), 129.0 (C-2', 6'), 132.4 (C-1'), 154.9 (C-4'), 94.0 (C-6), 96.9 (C-8), 105.3 (C-10), 155.9 (C-5), 164.4 (C-7), 165.8 (C-9), 205.1 (C4). On the basis of these results, the structure of the apple's main polyphenol compound was identified as phloretin (Fig 1) [10].<smiles>O=C(CCc1ccc(O)cc1)c1c(O)cc(O)cc1O</smiles>

Figure 1: Chemical structure of phloretin

\section{Phloretin inhibits gastric cancer cell growth}

The result of MTT assay showed that BGC823 proliferation was inhibited by treatment with phloretin (Fig 2). The phloretin caused a sustained growth arrest of BGC823 in dosedependent manner.

\section{Soft agar colony formation assay}

Formation assay revealed the phloretin's antiproliferation effects in dose-dependent manner in BGC823 (Fig. 3). Phloretin effectively inhibited soft agar formation in BGC823 gastric cancer cell at the concentration of 10,20 and $30 \mu \mathrm{M}$.

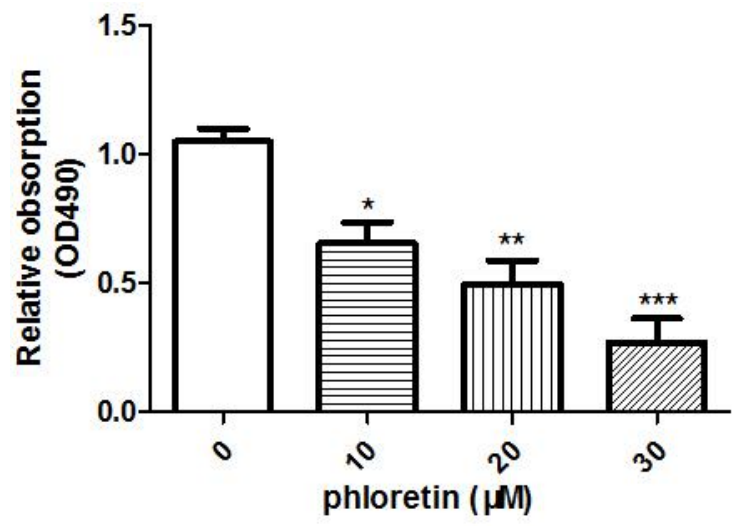

Figure 2: Anti-proliferation activity of phloretin in BGC823 cells. Data represent mean normalized optical densities \pm SEM $(\mathrm{n}=3)$; ${ }^{*} p<0.05,{ }^{* *} p<0.01$, ${ }^{* * *} p<0.001$ vs control

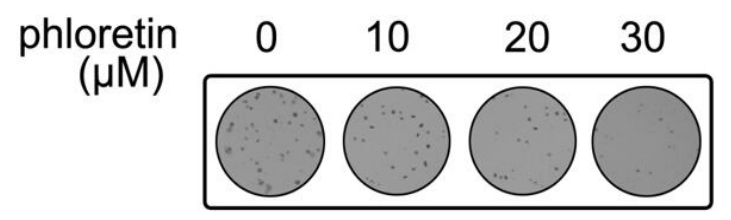

Figure 3: Representative photograph of colony formation. Phloretin inhibited the colony formation capacity in BGC823 in a dose-dependent manner

Phloretin induces apoptosis of BGC823 cells and modulates apoptosis-related protein expression

To investigate whether phloretin induce the apoptosis of gastric cancer cell, BGC823 cells were treated with 20 and $30 \mu \mathrm{M}$ phloretin for $24 \mathrm{~h}$ and then stained by DAPI (4,6-diamidino-2phenylindole) to investigated nuclear morphological changes under the treatment of phloretin. As observed in Fig 4, the untreated BGC823 cells displayed normal, healthy nuclear shapes, however the cells treated with 20 and 30 $\mu \mathrm{M}$ phloretin for $24 \mathrm{~h}$ showed morphological signs of apoptosis, which included chromatin condensation on the nuclear membrane (as indicated by arrow).

To confirm the induction of apoptosis and the anti-proliferation mechanism of phloretin in BGC823 gastric cancer cells, we further analyzed the protein expression of PARP, Bcl2 and Bax. Our results showed that 20 and $30 \mu \mathrm{M}$ phloretin effectively induced the cleavage of PARP in BGC823 cells after $24 \mathrm{~h}$ treatment (Fig 5). Furthermore, $\mathrm{Bcl} 2$ and Bax protein expression was detected by western blot. BGC823 treated with 20 and $30 \mu \mathrm{M}$ phloretin leaded to downregu- 

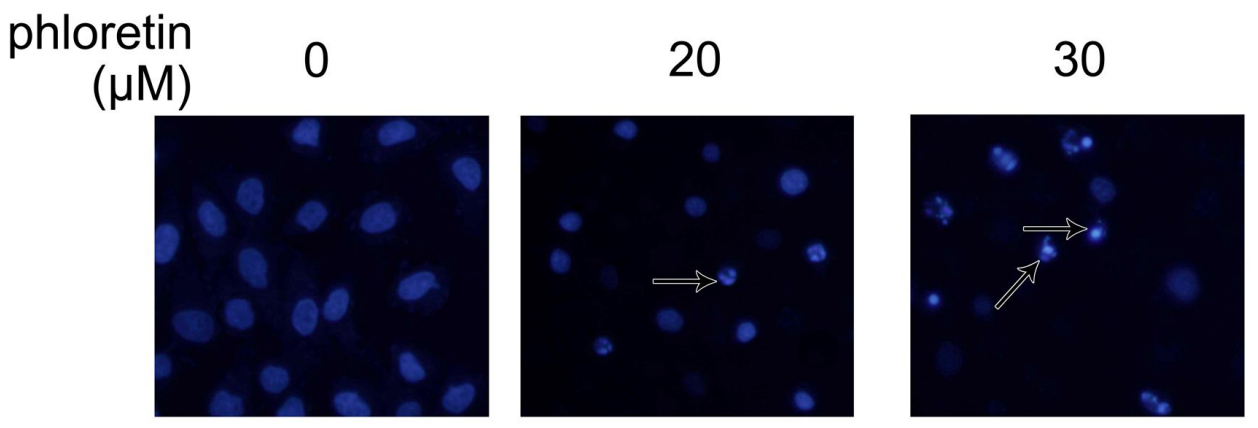

Figure 4: Apoptosis induced by phloretin in BGC823 cells. BGC823 cells treated with 20 and $30 \mu \mathrm{M}$ phloretin for $24 \mathrm{~h}$ and immunostained with DAPI. Note: An arrow points to apoptotic cells

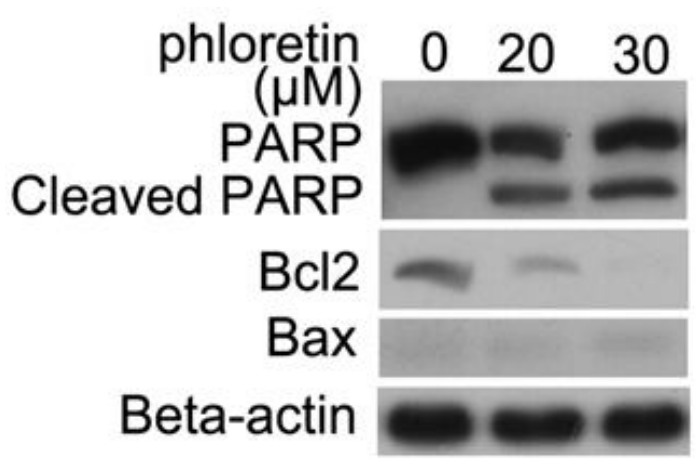

Figure 5: Apoptosis induced by phloretin in BGC823 cells, as detected by Western blot analysis of PARP, $\mathrm{Bcl} 2$, Bax in BGC823 cells treated with treated with 20 and $30 \mu \mathrm{M}$ phloretin for $24 \mathrm{~h}$

lation of anti-apoptotic protein $\mathrm{Bcl} 2$, at the same time proapoptotic protein Bax expression was constant (Fig 5).

\section{DISCUSSION}

Gastric cancer is still the second leading cause of cancer deaths, in spite of the application of numerous diagnostic tools [14]. Antioxidant intake, especially fresh fruits and vegetables have a preventive effect on stomach tumorigenesis. Phloretin is a chalcone, a type of natural flavonoid found in fruits and vegetables. Flavonoids are well known as antioxidant agents. Phloretin has been reported to inhibit liver cancer [15], breast cancer [16], colon cancer [17], while, its antineoplastic effect on gastric cancer cell is still unclear. In our study we found that 10, 20, 30 $\mu \mathrm{M}$ phloretin significantly inhibit BGC823 gastric cancer cell proliferation by MTT assay. Phloretin (30 $\mu \mathrm{M})$ almost completely inhibited soft agar colony formation in BGC823. Apoptosis induced by phloretin is an important way to inhibit the cancer cell growth.

Microscopy has been employed to investigate cytological appearance changes and to detect the cleavage of PARP by Western blotting. Cleavage of PARP, which is a DNA repair enzyme and facilitates cellular disassembly, is the markers of the cells that undergoing apoptosis. The results indicated that incubation of BGC823 cells with 20 and $30 \mu \mathrm{M}$ phloretin for $24 \mathrm{~h}$ resulted in numerous cells that had smaller nuclei with chromatin condensation and perinuclear apoptotic bodies. PARP levels in BGC823 cells were detected after exposure to phloretin by western blotting. The results indicate that 20 and $30 \mu \mathrm{M}$ phloretin can induce PARP cleavage in a dose-dependent manner. The apoptotic-preventing protein $\mathrm{Bcl} 2$ and the proapoptotic protein Bax were also detected; the $\mathrm{Bcl}$ 2/Bax ratios determine sensitivity to different apoptotic stimuli. In present study, 20 and $30 \mu \mathrm{M}$ phloretin resulted in downregulation of $\mathrm{Bcl} 2$ protein expression; however, Bax protein expression showed no change.

Taken together, the results show that phloretin inhibits BGC823 proliferation through downregulation of $\mathrm{Bcl} 2$ expression and induction of apoptosis.

\section{CONCLUSION}

Phloretin is the main polyphenol compound of apple plant and also is a promising cancer preventive and therapeutic agent for gastric cancer. Further studies are, however, required ascertain the clinical efficacy of the compound in gastric cancer therapy.

\section{REFERENCES}

1. Yuasa Y. Control of gut differentiation and intestinal-type gastric carcinogenesis. Nat Rev Cancer 2003; 3(8): 592-600.

2. Lin SW, Fan JH, Dawsey SM, Taylor PR, Qiao YL, Abnet CC. Serum thyroglobulin, a biomarker for iodine deficiency, is not associated with increased risk of 
upper gastrointestinal cancers in a large Chinese cohort [J]. Int J Cancer, 2011, 129(9): 2284-2289.

3. Muhammad JS, Sugiyama T, Zaidi SF. Gastric pathophysiological ins and outs of helicobacter pylori: a review. J Pak Med Assoc 2013; 63(12): 1528-1533.

4. Gonzalez CA, Sala $N$, Rokkas T. Gastric cancer: epidemiologic aspects. Helicobacter 2013; 18(Suppl 1): $34-38$

5. Rezk BM, Haenen GR, Van der Vijgh WJ, Bast A. The antioxidant activity of phloretin: the disclosure of a new antioxidant pharmacophore in flavonoids. Biochem Bioph Res Co 2002; 295(1): 9-13.

6. Huang WC, Chang WT, Wu SJ, Xu PY, Ting NC, Liou CJ. Phloretin and phlorizin promote lipolysis and inhibit inflammation in mouse 3T3-L1 cells and in macrophage-adipocyte co-cultures. Mol Nutr Food Res 2013; 57(10): 1803-1813.

7. Kobori M, Iwashita K, Shinmoto H, Tsushida T. Phloretininduced apoptosis in B16 melanoma $4 A 5$ cells and HL60 human leukemia cells. Biosci Biotech Bioch 1999; 63(4): 719-725.

8. Lee KW, Kim YJ, Kim DO, Lee HJ, Lee CY. Major phenolics in apple and their contribution to the total antioxidant capacity. J Agric Food Chem 2003; 51(22): 6516-6520.

9. Hilt P, Schieber A, Yildirim C, Arnold G, Klaiber I, Conrad $J$, Beifuss $U$, Carle R. Detection of phloridzin in strawberries (Fragaria $x$ ananassa Duch.) by HPLCPDA-MS/MS and NMR spectroscopy. J Agric Food Chem 2003; 51(10): 2896-2899.

10. Xü K, Lü H, Qü B, Shan H, Song J. High-speed countercurrent chromatography preparative separation and purification of phloretin from apple tree bark. Sep Purif Technol 2010; 72(3): 406-409.

11. Raja MM, Tyagi NK, Kinne RK. Phlorizin recognition in a C-terminal fragment of SGLT1 studied by tryptophan scanning and affinity labeling. I Biol Chem 2003; 278(49): 49154-49163.

12. Stangl V, Lorenz M, Ludwig A, Grimbo N, Guether C, Sanad W, Ziemer S, Martus P, Baumann G, Stangl K. The flavonoid phloretin suppresses stimulated expression of endothelial adhesion molecules and reduces activation of human platelets. J Nutr 2005; 135(2): 172-178.

13. Green MR, Sambrook J. Molecular cloning: a laboratory manual (M). New York: Cold Spring Harbor Laboratory Press, 2012.

14. Rahman $R$, Asombang A W, Ibdah J A. Characteristics of gastric cancer in Asia [J]. World journal of gastroenterology, 2014, 20(16): 4483.

15. Wu CH, Ho YS, Tsai CY, Wang YJ, Tseng H, Wei PL, Lee $\mathrm{CH}$, Liu RS, Lin SY. In vitro and in vivo study of phloretin-induced apoptosis in human liver cancer cells involving inhibition of type II glucose transporter. Int J Cancer 2009; 124(9): 2210-2219.

16. Kim MS, Kwon JY, Kang NJ, Lee KW, Lee HJ. Phloretin induces apoptosis in H-Ras MCF10A human breast tumor cells through the activation of p53 via JNK and p38 mitogen-activated protein kinase signaling. Ann NY Acad Sci 2009; 1171: 479-483.

17. Park SY, Kim EJ, Shin HK, Kwon DY, Kim MS, Surh YJ, Park JH. Induction of apoptosis in HT-29 colon cancer cells by phloretin. J Med Food 2007, 10(4): 581-586. 